\title{
Effect of Oral Zinc Supplementation on the Growth of Preterm Infants
}

\author{
Sunil Sazawal ANd Robert E Black \\ Department of International Health, Johns Hopkins Bloomberg School of Public Health, 615, North Wolfe Street, \\ Room E8527, Baltimore, MD 21205,USA.rblack@jhsph.edu
}

$\mathrm{P}$ reterm infants are at increased risk of death, acute and long-term morbidity; often associated with nutritional compromise and impaired growth. With about 13 million preterm babies born each year worldwide, the burden is disproportionately concentrated in Africa and Asia, where about $85 \%$ of all preterm births occur (31\% and 54\%, respectively)(1). Preterm and low birth weight babies may have impaired zinc status due to low body stores, limited capacity to absorb and retain micronutrients coupled with increased endogenous losses associated with organ immatu-rity, high nutrient demand to support catch-up growth, and inadequate intakes because exclusive breastfeeding does not compensate for increased demand due to prematurity. Preterm infants have high zinc deficit and dietary requirements as $60 \%$ fetal zinc is acquired during third trimester of pregnancy. Zinc deficiency has a negative effect on endocrine system leading to growth failure among other clinical manifestations.

In this issue of Indian Pediatrics, Islam and colleagues report the findings of a double blind randomized controlled trial evaluating the efficacy of oral zinc supplementation on the growth of hospital born preterm infants in the Neonatal Special Care Unit of Dhaka in Bangladesh(2). This is the first study carried out selectively among preterm babies to evaluate the effect of zinc supplementation in a developing country setting. In this study, 100 preterm infants (below 37 weeks of gestation) weighing between $1000 \mathrm{~g}$ and $<2500 \mathrm{~g}$ were enrolled and randomized to receive either zinc and multivitamin supplement (Group I; $n=50$ ) or only multivitamin supplement (Group II; $n=50$ ) for 6 weeks. At enrollment, serum zinc levels were in the lower limit of the normal range. The investigators concluded that zinc supplementation among preterm babies for 6 weeks resulted in improved weight gain and linear growth, enhanced serum zinc status and reduced incidence of diarrhea. There were no significant side effects of the supplements. The limitations of the study reported by authors included: infants were not followed up actively on daily basis to check compliance, and a long-term follow-up was not undertaken. However with observed change in plasma zinc concentration and growth impact, compliance does seem to have been adequate. Supplementation was given for shorter duration (6 weeks) whereas in the previously conducted studies in preterm infants the average period of supplementation was for 6 months $(3,4)$. It would have been of interest to evaluate sustainability of improved growth because shorter period of supplementation may in fact be more pragmatic and achievable in routine care.

So far only a few double blind randomized controlled trials, three from developed country settings(3-5), two of which were in premature infants, and five from developing country settings(6-10), have reported the effects of zinc supplementation during the first months of life on growth of infants born prematurely or small for their gestational age. The dose in these studies varied between $3 \mathrm{mg}$ to 10 $\mathrm{mg}$ of zinc per day. Of the 3 studies conducted in developed countries (Spain and Canada), 2 studies among preterm infants showed positive effect on plasma zinc concentrations and linear growth $(3,4)$ and 1 on LBW infants showed no effect(5). However, no significant effect on weight gain was 
observed in any of these studies(3-5). The available evidence for the effect of zinc supplementation on growth among low birth weight infants from developing countries setting is from India (2 studies)(6,7), Bangladesh (1 study)(8), Chile (1 study)(9) and Brazil (1 study)(10). The duration of supplementation in these studies ranged from 4 weeks to 1 year and the dosage of zinc supplement varied between $3 \mathrm{mg}$ to $5 \mathrm{mg}$ per day in first 6 months of age and $10 \mathrm{mg}$ of zinc per day for $>6-12$ months. Both short term $(4-6$ weeks $)(8,10)$ and long term ( 6 months-1 year) $(6,7,9)$ zinc supplementation had a beneficial effect on weight gain. However, only 2 long term supplementation studies conducted in India and Chile documented a significant increase in length gain with zinc supplementation(7,9). On the contrary, the largest RCT conducted on LBW Indian infants concluded no beneficial effect on length and weight gain with zinc supplementation given for a period of 1 year, although a positive effect on plasma zinc concentration was observed(6). There are bound to be physiological differences between the preterm births and non-preterm small for gestational age births because the period available for zinc accumulation during gestation is different. Therefore some of the conflicting data regarding impact of zinc on growth in low birth weight infants may be contributed by mixing low birth weight and preterm births. Most of the studies that have evaluated impact in low birth weight infants in developing countries have not reported gestational age due to difficulty of ascertaining it and so would have recruited a variable mixture of preterm births and small for gestational babies. In the light of available evidence, the findings of the current study provide an important piece of additional data, which needs further confirmation. If replicated, zinc supplementation as an intervention to improve growth of hospital born preterm infants in developing country settings would be an inexpensive and easy intervention to scale up and even take to community service delivery. Studies with adequate sample size, preferably multicentre and with longerterm follow up are needed to confirm and quantify the magnitude of the beneficial effect of zinc supplementation on growth among preterm babies.

Competing interests: None stated.

Funding: None.

INDIAN PEDIATRICS

\section{REFERENCES}

1. Beck S, Wojdyla D, Say L, Betran AP, Merialdi M, Requejo $\mathrm{JH}$, et al. The worldwide incidence of preterm birth: a systematic review of maternal mortality and morbidity. Bull World Health Organ 2010; 88: 31-38.

2. Islam MN, Chowdhury M, Siddika M, Qurishi SB, Bhuiyan MK, Hoque MM, et al. Effect of oral zinc supplementation on the growth of preterm infants. Indian Pediatr 2010; 47: 845-849.

3. Díaz-Gómez NM, Doménech E, Barroso F, Castells S, Cortabarria C, Jiménez A. The effect of zinc supplementation on linear growth, body composition, and growth factors in preterm infants. Pediatrics 2003; 111: 1002-1009.

4. Friel JK, Andrews WL, Matthew JD, Long DR, Cornel AM, Cox M, et al. Zinc supplementation in very low birth weight infants. J Pediatr Gastroenterol Nutr 1993; 17: 97-104.

5. Bueno O, Bueno G, Moreno LA, Nuviala RJ, Pérez-González JM, Bueno YM. Zinc supplementation in infants with asymmetric intra uterine growth retardation; effect on growth, nutritional status and leptin secretion. Nutr Hosp 2008; 23: 212-219.

6. Taneja S, Bhandari N, Rongsen-Chandola $\mathrm{T}$, Mahalanabis D, Fontaine O, Bhan MK. Effect of zinc supplementation on morbidity and growth in hospital-born, low-birth-weight infants. Am J Clin Nutr 2009; 90: 385-391.

7. Sur D, Gupta DN, Mondal SK, Ghosh S, Manna B, Rajendran K, et al. Impact of zinc supplementation on diarrhoeal morbidity and growth pattern of low birth weight infants in Kolkata, India: A randomized, double-blind, placebo-controlled, community-based study. Pediatrics 2003; 112: 1327-1332.

8. Hoque A, Ali SMK. Role of zinc in low birth weight neonates. Bangladesh Med J 2009; 38: 24-30.

9. Castillo-Duran C, Rodriguez A, Venegas GV, Alvarez P, Icaza P. Zinc supplementation and growth of infants born small for gestational age. $\mathrm{J}$ Pediatr 1995; 127: 206-211.

10. Lira PI, Ashworth A, Morris, SS. Effect of zinc supplementation on the morbidity, immune function and growth of low birth weight, full term infants in northeast Brazil. Am J Clin Nutr 1998; 68: 418-423. 